\title{
Quaderni
}

QUADERNI Communication, technologies, pouvoir

83 | Hiver 2013-2014

Le public de la danse contemporaine

\section{Aurélie Olivesi. Implicitement sexiste? Genre, politique et discours journalistique}

Brigitte Rollet

\section{OpenEdition}

Édition électronique

URL : http://journals.openedition.org/quaderni/781

DOI : 10.4000/quaderni.781

ISSN : 2105-2956

Éditeur

Les éditions de la Maison des sciences de l'Homme

Édition imprimée

Date de publication : 5 janvier 2014

Pagination : 123-124

Référence électronique

Brigitte Rollet, "Aurélie Olivesi. Implicitement sexiste ? Genre, politique et discours journalistique », Quaderni [En ligne], 83 | Hiver 2013-2014, mis en ligne le 01 janvier 2016, consulté le 25 septembre 2020. URL : http://journals.openedition.org/quaderni/781 ; DOI : https://doi.org/10.4000/quaderni.781 


\section{Compte rendu}

\section{Implicitement sexiste? \\ Genre, politique et discours journalistique}

\section{Aurélie Olivesi}

Les presses universitaires du Mirail, Toulouse, 2012

par Brigitte Rollet

Université de Versailles Saint-Quentin

CHCSC

Issu de sa thèse en sciences de l'information et de la communication, l'ouvrage d'Aurélie Olivesi s'attache à l'étude du discours médiatique qui a accompagné une nouveauté de la vie politique française, à savoir la présence d'une femme au second tour de l'élection présidentielle de 2007. Ce « discours de la presse » s'appuie selon l'auteure, à la fois sur la citation d'autrui, la présence du locuteur étant donc ainsi quelque peu occultée ( « énonciation plutôt objectivée »), ou au contraire, sur le commentaire où domine la subjectivité ( «énonciation plutôt subjectivée »), les stéréotypes de genre dans l'expression (locutions figées) ou, à l'inverse, l'absence de discours grammaticalement genré dans l'écriture du/de la politique qui, de fait, contribue à l'exclusion des femmes du champ.

À partir d'une analyse de discours des propos contenus dans les articles que les médias français ont consacrés à la candidate sur une durée de pratiquement un mois (du 9 avril au 7 mai, c'est-à-dire selon l'auteure, deux semaines avant et deux semaines après le premier tour et permet à la fois la présence de « rituels de campagne » et de « routines journalistiques »). Elle articule à cette analyse une démarche genrée, visant à démontrer à la fois l'intégration notable d'un discours relativement paritaire, avec une pérennité et des manifestations multiples d'un sexisme tenace : dans la perception, la présentation et la recension des activités de Ségolène Royal par la presse française, une misogynie qui ne dirait plus son nom aussi ouvertement que dans le passé, s'exprime néanmoins. Contrairement à ce que l'on a pu constater durant la précédente élection (voir les travaux de Cécile Sourd pour 2002 auxquels Olivesi fait référence), elle avance masquée. Les éditorialistes semblent se 
« cacher » le plus souvent derrière les propos supposément tenus par des politiques sur la candidate malheureuse du second tour. Il apparaît en effet, selon l'auteure, y avoir eu une sorte de double discours par lequel les journalistes font endosser à d'autres non nommés (le « off the record », l'anonymat des « Français »), des points de vue et commentaires très stéréotypés et parfois ouvertement misogynes, dont on peut se demander jusqu'à quel point ils sont partagés par ceux qui les rapportent.

L'intérêt premier de l'ouvrage vient de la recension d'une sorte de florilège d'une langue qui sans être à proprement parler « de bois », n'en est pas moins étonnamment évocatrice des lenteurs dans les esprits de la légitimité des femme en politique en France, presque une douzaine d'années quand même après l'adoption de la loi sur la parité en politique (2001). La manière dont est présentée la candidate (fille spirituelle de l'un, compagne de l'autre, fille de son père) n'est pas nouvelle et nombreuses sont les femmes en politique, de droite comme de gauche et quelle que soit l'élection, à ne pas sembler posséder, dans les médias du moins, d'identité propre. De la même manière, le choix du prénom pour les identifier, la référence quasi systématique à leur physique d'une façon qui les renvoie mécaniquement à leur sexe et aux stéréotypes les plus archaïques, si elle a été décuplée durant cette campagne, n'en est pas moins une constante du discours médiatique sur les femmes en/ politique.

L'auteure ne se cantonne pas à la construction du féminin offert par ces discours médiatiques, mais s'intéresse également à la "virilité » de son adversaire telle qu'en rendent compte les mêmes journalistes. Tout se passe comme si, dans cette élection-là, il ne s'agissait pas tant de rendre compte d'un combat politique (et donc d'idées ou d'idéologie) en vue de la magistrature suprême, que d'une opposition fortement genrée entre un homme et une femme, chacun fourbissant les « armes » réelles ou supposées de son identité de sexe, et ce, alors même que les journalistes font comme si le genre ne comptait pas.

Qui s'intéresse aux médias et à la presse écrite pourra regretter que toutes les publications soient mises sur le même plan sans réelle distinction (tirage, lectorat, obédience). Ceci n'affecte cependant pas la rigueur de l'exposé et la richesse de l'analyse qui démontre, à qui en doutait encore, du poids des préjugés de sexe dans la société et la politique françaises. 